\title{
O PROFISSIONAL DE SECRETARIADO EXECUTIVO COMO MEDIADOR DE CONFLITOS
}

\section{SECRETARIAT OF THE PROFESSIONAL EXECUTIVE AS MEDIATOR OF CONFLICT}

\section{Katia Denise Moreira}

Especialização em MBA em Gestão de Pessoas e Processos pelo Complexo de Ensino Superior de Santa Catarina - CESUSC

Secretária Executiva dos Orgãos Deliberativos Centrais da Universidade Federal de Santa Catarina - UFSC

E-mail: katiadenise@yahoo.com.br (Brasil)

\section{Luis Carlos Cancellier de Olivo}

Doutor em Direito pela Universidade Federal de Santa Catarina - UFSC

Professor da Universidade Federal de Santa Catarina - UFSC

E-mail: cancellier@uol.com.br (Brasil) 


\title{
O PROFISSIONAL DE SECRETARIADO EXECUTIVO COMO MEDIADOR DE CONFLITOS
}

\section{RESUMO}

Neste estudo, pretende-se investigar se as habilidades, competências e atitudes que compõem o novo perfil do profissional de Secretariado Executivo, associado ao caráter multifuncional e polivalente da profissão, permitem a esse profissional assumir a posição de mediador de conflitos. A metodologia é predominantemente de abordagem qualitativa e, de acordo com os objetivos, descritiva, embasada na análise bibliográfica e de documentos. O resultado evidencia que o profissional de Secretariado Executivo está apto a exercer a mediação de conflitos.

Palavras-chave: Secretariado Executivo; Gestão de Conflitos; Mediação de Conflitos.

SECRETARIAT OF THE PROFESSIONAL EXECUTIVE AS MEDIATOR OF CONFLICT

\begin{abstract}
This paper intends investigate if the skills, abilities and attitudes that arrange the new profile of the executive secretarial professional, in addition of the versatility and multifunctional nature of the profession, allow this professional to assume the position of conflicts mediator. The methodology is predominately qualitative and in accordance with the objectives is descriptive, based on literature review and documents relating to the subject. The results show that the professional executive secretarial is able to exercise mediation conflict.
\end{abstract}

Keywords: Executive Secretary Professional; Conflict Management; Conflict Mediation. 


\section{INTRODUÇÃO}

Contemporaneamente percebe-se o mercado de trabalho mais competitivo a cada dia. Evidenciam tal afirmação os desafios que se tornaram uma constante e o fato de que uma carreira linear não se ajusta mais aos perfis profissionais atuais. Exige-se, hoje, planejamento profissional. Entretanto o indivíduo precisa estar preparado para mudanças nesse projeto e, nesse sentido, a busca pela atualização de competências pessoais, sociais e profissionais deve ser entendida como uma essencialidade.

Nesse contexto, insere-se o profissional de Secretariado Executivo que - após um longo período em busca de aprimoramento, tanto para a melhor realização de suas tarefas, quanto pela valorização de seu trabalho - assume, atualmente, na estrutura organizacional, um caráter multifuncional. Isso significa que o trabalho é agora diversificado e dinâmico; fato que, somado à importância em tratar novas possibilidades de atuação dentro da transversalidade oportunizada pela carreira de Secretário Executivo, define a proposta deste trabalho, o qual sugere o estudo do problema: valendo-se das habilidades, competências e atitudes que compõem o novo perfil do profissional de Secretariado Executivo, é possível que esse profissional assuma a posição de mediador de conflitos dentro da organização?

Este estudo justifica-se pela constatação da pouca ocorrência de bibliografia que trata da relação entre a gestão de conflitos e o profissional de secretariado, na observação de que, apesar da evidente evolução da profissão, ainda se enfrentam situações de preconceito em algumas organizações. E, também, pelo fato de que é necessário trabalhar constantemente a profissão, a fim de valorizá-la cada vez mais.

Pressupõe-se que a experiência desse profissional em lidar com situações conflitantes no cotidiano organizacional, somada ao conhecimento aprofundado de técnicas e ferramentas específicas, fornecem subsídios para que ele obtenha um bom desempenho na execução da mediação de conflitos. Todavia, observa-se que - além das características necessárias a um mediador - é essencial ao profissional: forte comprometimento organizacional, empenho na busca pelo conhecimento, determinação para comprovar sua capacidade e bom senso para fazer escolhas acertadas bem como proferir opiniões coerentes.

Revista de Gestão e Secretariado - GeSec, São Paulo, v. 3, n. 1, p 30-53, jan./jun. 2012. 


\section{PROCEDIMENTOS METODOLÓGICOS}

A fim de estabelecer ações que possibilitem alcançar o objetivo deste estudo, optou-se por utilizar uma combinação de procedimentos metodológicos, os quais foram aplicados de forma a viabilizar a investigação proposta, conforme considera Gil (1991, p.19): “a pesquisa é desenvolvida mediante o concurso dos conhecimentos disponíveis e a utilização cuidadosa de métodos, técnicas e outros procedimentos científicos".

No que concerne ao problema de pesquisa - valendo-se das habilidades, competências e atitudes que compõem o novo perfil do profissional de Secretariado Executivo -, é possível que esse profissional assuma a posição de mediador de conflitos dentro da organização? Em relação à finalidade, esta pesquisa pode ser dita aplicada, uma vez que está voltada à "aquisição de conhecimentos com vistas à aplicação numa situação específica” (Gil, 2010, p. 27). Quanto aos objetivos, trata-se de uma pesquisa descritiva, concordando com Gil (1991, p.46): “As pesquisas descritivas têm como objetivo primordial a descrição das características de determinada população ou fenômeno ou, então, o estabelecimento de relações entre as variáveis." No que diz respeito à abordagem, a pesquisa caracteriza-se como qualitativa.

O texto foi estruturado de forma a promover uma sequência lógica dos fatos e, nesse sentido, compõem a pesquisa: introdução, responsável por apresentar o tema proposto; referencial teórico, cuja estrutura está dividida da seguinte forma: descrição do profissional de Secretariado Executivo, aspectos gerais, características e atribuições contemporâneas, seguida por uma síntese daquilo que trata a gestão e mediação de conflitos; por fim, demonstra-se o proposto no objetivo deste trabalho, ou seja, identificar se o profissional de Secretariado Executivo tem competências e habilidades para exercer a mediação.

\section{REVISÃO BIBLIOGRÁFICA}

\subsection{O PROFISSIONAL DE SECRETARIADO EXECUTIVO}

O profissional de secretariado vem, ao longo de sua história, evoluindo no que diz respeito ao conceito da profissão. É notória a diferença existente entre as atribuições do passado e aquelas que, hoje, são executadas pelo profissional. Entretanto a busca pela valorização no sentido de alcançar um status de maior visibilidade e responsabilidade dentro das organizações é uma constante.

Revista de Gestão e Secretariado - GeSec, São Paulo, v. 3, n. 1, p 30-53, jan./jun. 2012. 
Um exemplo do exposto é observado, contemporaneamente, nas palavras da consultora de empresas e relações públicas da Associação Europeia de Secretárias Profissionais, Christine Davies, no artigo A secretária do futuro (2010), quando comenta que o tempo em que esse profissional era contratado apenas para servir café, datilografar/digitar bem e ter boa aparência ficou no passado. Na nova estrutura organizacional, o secretário executivo assume responsabilidades como, por exemplo, as de gerenciamento e gestão.

Por outro lado, é indispensável que o profissional de secretariado tenha consciência de seu novo papel no ambiente organizacional. Ou seja, não basta perceber que houve uma evolução; é preciso que o profissional compreenda que suas funções sofreram alterações no sentido da progressão e que uma nova postura deve ser adotada, na qual a inovatividade, resiliência e polivalência são agora elementos essenciais.

Tratando do conceito da profissão, constata-se que a maioria dos autores embasa sua definição nas tarefas e atribuições a serem executadas pelo profissional, fato que a torna um tanto quanto subjetiva.

Natalense (1998, p. 4) afirma: “A profissão de secretária é uma das que acompanham o desenvolvimento econômico da humanidade, ao longo dos séculos, sobrevivendo a diferentes realidades".

Guimarães enfatiza a importância do profissional como elemento de comunicação dentro da empresa:

Quando as secretárias afirmam que "são o coração da empresa" e que "sem elas nada funcionará direito", acreditamos ser correta essa observação, pois elas funcionam como vetor de comunicações da empresa, tanto interna quanto externamente. Esse canal de comunicação é de vital importância para o sucesso de qualquer empreendimento. (Guimarães, 1999, p. 298).

Ching sintetiza interessantemente o papel do profissional de secretariado no ambiente organizacional:

[...] capazes de ofuscar a sensação de impotência diante de certas situações; conquistar espaço pelo carisma; trabalhar com a paciência no limite; organizar agendas, viagens e documentos; lembrar os menores até os mais importantes assuntos; lidar com diversas falhas do departamento; beirar a perfeição e, acima de tudo, manter o ânimo da equipe [...] (Ching, 2006, p 13).

Wanser (2009), em curso de especialização - Master Business Secretaries (MBS) - PósGraduação em Secretariado Gestão de Pessoas e Processos - definiu o profissional de Secretariado Executivo de forma bastante contemporânea: "organizador e harmonizador do ambiente de 
trabalho; maximizador e otimizador do tempo (de quem?); interface entre dirigentes, equipe de trabalho, clientes internos e externos e fornecedor de subsídios para tomada de decisões”.

Todavia, a lei federal que regulamenta a profissão - Lei n. 7377, de 30 de setembro de 1985, complementada pela Lei n. 9261, de 11 de janeiro de 1996, dispõe de forma objetiva em seu artigo segundo que: "Secretário Executivo é o profissional diplomado no Brasil por curso superior de Secretariado, reconhecido na forma da Lei, ou diplomado no exterior por curso superior de Secretariado, cujo diploma seja revalidado no Brasil, na forma da Lei” (Brasil, 1985).

Vale dizer ainda que a amplitude da atuação do profissional de Secretariado Executivo é determinada pela estrutura e natureza da organização, bem como pela forma de administração dos líderes, os quais serão os responsáveis por definir a forma de assistência que será desempenhada pelo profissional; o certo é que será sempre ao lado daqueles que têm o poder de decisão.

\subsubsection{TRAJETÓRIA PROFISSIONAL}

Ao analisar a história da humanidade, constata-se que a profissão de Secretariado Executivo tem alguns milhares de anos, dentre os quais se observam períodos de auge e de decadência, bem como momentos em que os homens eram os representantes únicos de uma classe que é hoje ocupada, na maioria das ocorrências, pelas mulheres.

Tratando brevemente da história do profissional de secretariado, Natalense (1998, p. 4) expõe que: “através de pesquisa histórica, percebemos que o 'antepassado' da secretária foi o escriba - profissional de atuação destacada em toda a Idade Antiga, junto aos povos que desenvolveram a escrita e o comércio".

Em relação à Idade Média, a autora destaca que o papel do profissional de secretariado passou despercebido, visto as condições políticas, econômicas e sociais que caracterizaram aquela época. Ainda de acordo com a autora, os monges, em geral, atuavam como copistas e arquivistas (Natalense, 1998).

O ressurgimento da profissão aconteceu durante a Revolução Comercial (1400-1700), seguido por um período de maior destaque durante a Revolução Industrial. “O secretário passa a atuar nesta nova sociedade industrial e o seu papel torna-se comum na Segunda Fase da Revolução Industrial (a partir de 1860) com o advento da máquina de escrever” (Natalense, 1998, p. 6).

Natalense (1998) comenta também que os trabalhos secretariais eram até os anos cinquenta desenvolvidos por homens:

Revista de Gestão e Secretariado - GeSec, São Paulo, v. 3, n. 1, p 30-53, jan./jun. 2012. 
A profissão mantém-se eminentemente masculina até o século XX. A situação começa a mudar com as duas guerras mundiais que provocam a entrada da mulher no mercado de trabalho, em áreas além da produção. A partir de então e até os nossos dias, a profissão torna-se eminentemente feminina. (Natalense, 1998, p. 6).

Ainda segundo a autora, no Brasil "o desenvolvimento da profissão acompanha exatamente o desenvolvimento gerencial, revelando as características gerenciais de cada década". (Natalense, 1998, p. 7).

Em relação ao contexto brasileiro, ressalta-se que o Brasil é um dos países que mais progrediu na área do secretariado. No País a função é regulamentada por lei, fato que a justifica e valida como uma profissão. Em 30 de setembro de 1985, foi publicada no Diário Oficial da União a Lei 7.377, que dispõe sobre o exercício da profissão de secretariado e dá outras providências. Em 1987 o Ministério do Trabalho, por meio da Portaria n. ${ }^{\circ}$ 3103, reconhece a profissão como Categoria Diferenciada. Em 1989, foi publicado o Código de ética do profissional de Secretariado Executivo, e em 10 de janeiro de 1996, a Lei n. 9.261 faz pequena alteração na Lei n. 7.377.

\title{
3.1.2 ATRIBUIÇÕES DO SECRETÁRIO EXECUTIVO CONTEMPORÂNEO
}

Diferentemente daquilo que era realizado no passado, hoje o profissional de secretariado tem competências específicas, dentre as quais se incluem: as técnicas, as de comunicação e as sociais. Analisando os fatos, a partir daquilo que era executado no passado (Quadro 1), pode-se concluir que o profissional foi praticamente forçado a reciclar-se, e aqueles que se mostraram resistentes às mudanças foram perdendo lugar para os que buscam aprimoramento, conhecimento e novas possibilidades dentro da carreira. Nesse contexto, Carvalho e Grisson (2002) comentam as competências atuais do profissional e a necessidade de aperfeiçoamento profissional:

\begin{abstract}
Atualmente, estas profissionais buscam ferramentas para administrar eficazmente o tempo; aplicam as funções gerenciais (planejamento, organização, controle e direção); dão ênfase ao relacionamento com os clientes (internos e externos); valorizam os princípios de um sistema de comunicação; possuem habilidade para o trabalho em equipe na busca de sinergia; resolvem problemas inerentes ao seu trabalho, melhorando a qualidade e a produtividade dos serviços; procuram obter uma visão geral da cultura da organização; conhecem e aplicam elementos de psicologia, cultivando a habilidade nas relações pessoais, ou seja, habilidade no trato das pessoas, respeitando suas diferenças individuais e as diversas situações que as envolvem; assim como habilidade e capacidade para perceber a necessidade constante de aperfeiçoamento profissional, acompanhando a evolução científica e tecnológica (Carvalho e Grisson, 2002, p. 452).
\end{abstract}

O quadro, a seguir, complementando o exposto, ilustra as mudanças ocorridas entre as atividades exercidas no passado e as atribuições de hoje:

Revista de Gestão e Secretariado - GeSec, São Paulo, v. 3, n. 1, p 30-53, jan./jun. 2012. 


\begin{tabular}{|c|c|}
\hline \multicolumn{2}{|c|}{ A VALORIZAÇÃO DAS RESPONSABILIDADES DA SECRETÁRIA } \\
\hline ANTES & DEPOIS \\
\hline * Executora de rotinas & * Gerenciamento da execução de rotinas \\
\hline * Datilógrafa & * Editora de textos \\
\hline * Arquivista & $\begin{array}{l}\text { * Planejadora, organizadora e mantenedora de dados e } \\
\text { informações em arquivos, inclusive eletrônicos }\end{array}$ \\
\hline * Atendente de telefone & * Atendimento global aos clientes \\
\hline * Quebra-galhos & $\begin{array}{l}\text { * Intermediadora de acontecimentos, negociadora, } \\
\text { facilitadora }\end{array}$ \\
\hline * Mecânica & * Criativa \\
\hline * Submissa & * Empreendedora \\
\hline * Dependente & * Autônoma \\
\hline * Disponível & * Acessível \\
\hline * Seguidora & * Líder \\
\hline * Resolvedora de problemas & * Realizadora de previsões objetivas \\
\hline * Cartão de visitas & * Agente de marketing e endomarketing \\
\hline
\end{tabular}

Quadro 1 - A valorização das responsabilidades da secretária.

Fonte: Natalense (1998, p.48).

A comparação entre os perfis do profissional de secretariado de ontem e de hoje evidencia que as competências do secretário executivo mudaram; as atividades meramente mecânicas dos anos sessenta e setenta estão em processo de extinção. Atualmente, o mercado busca um profissional de atitude, com uma postura pró-ativa e não um simples executor de tarefas. Hoje, falase em coparticipação no processo gerencial. Carvalho e Grisson (2002, p. 447), confirmam o 
exposto quando comentam: “A Secretária Executiva deixou de ser uma executora de pequenas tarefas para exercer funções criativas [...]”.

Percebe-se que as tendências de mercado para o profissional de secretariado são bastante promissoras e que cabe a este a busca por novas possibilidades dentro de sua carreira. Uma delas é a proposta deste trabalho, ou seja, o profissional de secretariado como mediador de conflitos. Nesse sentido, concordam com o dito Carvalho e Grisson (2002, p. 454) quando expressam:

[...] existe a construção de um grande repertório de perfis profissionais, quer de perfis específicos a cada setor de atividade determinados pelas opções tecnológicas e os modos de organização do trabalho de cada setor, quer de perfis transversais a vários setores, que respondem a fatores críticos de competitividade.

Por fim, retoma-se o já exposto, ou seja, que o relevante progresso no papel organizacional do secretário executivo não aconteceu repentinamente, é resultado de um trabalho histórico de luta pelo reconhecimento. Guimarães (1999, p. 331) complementa tal afirmação quando expõe: “o novo conceito de valorização profissional ensina que somos nós, e não a empresa, os profissionais de nossas carreiras". Nesse contexto, compreende-se que cabe ao próprio profissional de Secretariado Executivo encontrar recursos que o transformarão em um elemento cada vez mais estratégico dentro da organização, sendo uma dessas possibilidades atuar na gestão de conflitos.

\subsection{GESTÃO DE CONFLITOS}

\subsubsection{ASPECTOS GERAIS}

Por gestão de conflitos entende-se: “identificá-lo, compreendê-lo, interpretá-lo e utilizá-lo para benefício de cada indivíduo, das famílias, dos grupos sociais, das organizações e, enfim, da sociedade" (Fiorelli; Fiorelli e Malhadas Junior, 2008, p. 6).

Nota-se que os conflitos estão presentes em todas as áreas das relações humanas; contudo, de acordo com o objetivo deste trabalho, será destacada a gestão de conflitos no ambiente organizacional, uma vez que é este o âmbito de trabalho do ator social da pesquisa.

Situações de conflito não surgem simplesmente, elas têm como ponto de partida uma conjuntura de diversidade. As diferenças podem acontecer por vários motivos, contudo sempre estarão inseridas em um contexto. Segundo Chiavenato (2000, p. 362): “O conflito pode ocorrer no contexto do relacionamento entre duas ou mais partes: pode ocorrer entre pessoas ou entre grupos e organizações. Também pode ocorrer entre mais de duas partes ao mesmo tempo".

Revista de Gestão e Secretariado-GeSec, São Paulo, v. 3, n. 1, p 30-53, jan./jun. 2012. 
Robbins (2005, p. 326) define conflito como um processo que tem início quando uma das partes percebe que a outra parte afeta, ou pode afetar negativamente alguma coisa que a primeira considera importante.

Para Wisinski (1995, p. 1) o conflito até pouco tempo estava "associado a comportamento indesejável, era visto como uma característica de indivíduos que não conseguiam se relacionar com os outros, que não faziam parte da equipe ou, simplesmente, não se encaixavam. A melhor maneira de lidar com o conflito era evitá-lo". Entretanto, o autor afirma que, atualmente, a forma de se observar os conflitos mudou notavelmente, e, hoje, é considerado, por muitos, como algo natural. O autor diz ainda que o conflito "é visto como uma dinâmica interpessoal e, quando tratado de maneira correta, pode ser ao menos administrado, muitas vezes resolvido e, provavelmente, terá resultados bastante criativos".

Conflitos têm sido frequentemente debatidos, principalmente no que diz respeito a suas características funcionais e disfuncionais, ou seja, quando tal tipo de situação melhora ou atrapalha o desenvolvimento do grupo. Robbins explica o dito da seguinte forma:

[...] alguns conflitos apoiam os objetivos do grupo e melhoram seu desempenho; estes são os conflitos funcionais, formas construtivas de conflito. Por outro lado, existem conflitos que atrapalham o desempenho do grupo; são formas destrutivas ou disfuncionais de conflito. (Robbins, 2005, p. 327, grifos do autor).

No caso proposto para estudo, por exemplo, um conflito de processo pode ser funcional quando os diferentes pontos de vista estimularem a criatividade e a partir daí surgirem ideias novas para o desenvolvimento das atividades; todavia pode ser disfuncional se a discussão gerar dúvidas sobre quem faz o que dentro do ambiente organizacional.

A fim de facilitar a apreciação de situações conflitantes, Robbins (2005) descreve o "processo do conflito", o qual pode ser utilizado como um modo prático de análise de conflitos. Ou seja, nos casos em que esse tipo de situação é detectado, aplica-se o método, a fim de detectar as fontes, avaliar comportamento e intenções das partes e diagnosticar as possíveis consequências dos fatos. A adoção de tal procedimento proporciona a adequada apreciação das situações e ações do conflito, facilitando a gestão e resolução de questões conflitantes.

Sabe-se que as organizações têm, ainda hoje, certa tendência a evitar conflitos; entretanto, observase que: "o conflito opõe-se a estagnação. Desempenha o papel de mola propulsora que permite à humanidade sobreviver em um planeta de recursos limitados" (Fiorelli; Fiorelli e Malhadas Júnior, 2008, p. 5).

Revista de Gestão e Secretariado - GeSec, São Paulo, v. 3, n. 1, p 30-53, jan./jun. 2012. 
Moscovici, em seu ponto de vista sobre conflito, não só corrobora com a posição anterior, como também destaca as funções positivas do conflito nas organizações. De um ponto de vista mais amplo, o conflito tem muitas funções positivas. Ele previne a estagnação decorrente do equilíbrio constante da concordância, estimula o interesse e a curiosidade pelo desafio da oposição, descobre os problemas e demanda sua resolução. Funciona, verdadeiramente, como raiz de mudanças pessoais, grupais e sociais (Moscovici, 1997, p. 146).

De acordo com tal posição, ou seja, a de administrar os conflitos sob a visão positiva, a literatura apresenta os modelos alternativos de solução de conflitos, dentre os quais se destacam a arbitragem, a negociação, a conciliação e a mediação. Segundo Fiorelli, Fiorelli e Malhadas Júnior (2008, p.51), “emprega-se o termo alternativo em relação ao método tradicional da busca ao Judiciário" (grifo do autor).

Conforme definido na metodologia desta pesquisa, a mediação como método alternativo de resolução de conflitos tem destaque, visto que é matéria ligada diretamente ao objetivo deste trabalho.

\subsubsection{A MEDIAÇÃO COMO MÉTODO ALTERNATIVO DE RESOLUÇÃO DE CONFLITOS}

Os métodos de solução de conflitos podem ser subdivididos de várias formas, dentre as quais se distinguem denominações como autocompositivas e heterocompositivas. A primeira referese aos métodos em que as partes buscam soluções sem a intervenção de terceiros, e a segunda, quando deixam a solução a cargo de outra pessoa.

Ao definir o melhor método para gerir situações de conflito no ambiente organizacional é preciso atentar para o histórico de cada situação. A resistência, característica daquele que defende seu ponto de vista, é comum em todos os níveis de conflito, e, sendo assim, é necessária muita habilidade para administrar ou mesmo solucionar situações desse tipo. Tratando-se da busca por um resultado positivo para tais circunstancias, é ainda mais desafiador chegar a um consenso, uma vez que é necessário transformar opiniões diversas em algo único e que satisfaça as partes envolvidas.

Nesse sentido, não há dúvidas de que o método escolhido deva ser aquele que não só trabalhe o equilíbrio das relações interpessoais, como também promova a "aprendizagem" para a organização como um todo. Senge (2006) destaca que a ideia de organização que aprende é uma visão, um ideal a que todos aspiram.

Sob esse olhar, a mediação é, possivelmente, o método mais adequado, visto que traz em sua essência o conceito de isonomia, ou seja, as partes são tratadas de forma idêntica, já que o que se busca nesse método de resolução de conflitos é o reconhecimento de diferenças. Estas serão aceitas

Revista de Gestão e Secretariado - GeSec, São Paulo, v. 3, n. 1, p 30-53, jan./jun. 2012. 
e entendidas, não para serem impostas, mas para construírem algo melhor (Fiorelli, Fiorelli e Malhadas Júnior, 2008).

Muszkat fortalece o dito acima, quando expõe: "é preciso esclarecer que não interessa à mediação saber com quem está a razão, e sim solucionar o problema” (Muszkat, 2005, p.79). Nesse sentido, o que se pretende ao aplicar a mediação é trabalhar o conflito sob a ótica social, ou seja, o indivíduo e sua satisfação são os pontos fundamentais.

Nesse contexto, cabe inserir o proposto por Guerreiro Ramos em a Nova ciência das organizações (1982), complementada pelo artigo A racionalidade substantiva demonstrada na prática administrativa (1997), ou seja, a mediação vislumbrada como uma ação de racionalidade substantiva, cujas ações são orientadas para a autorrealização, entendimento, julgamento ético, autenticidade, valores emancipatórios e autonomia. Em outras palavras, a mediação, promovendo uma relação de "ganha-ganha", na qual o entendimento entre as partes, a ética, a integridade, o respeito, a mudança no sentido da compreensão e a condição dos indivíduos de poderem agir de forma a solucionar o problema de forma livre e plena promoverão a autorrealização dos mediandos.

\subsubsection{O MEDIADOR DE CONFLITOS}

O mediador é o terceiro presente em uma sessão de mediação e tem a função de coordenação dos trabalhos. É ele o responsável por despertar o desejo de mudança entre as partes. É válido reforçar que não é ele quem indica a solução do conflito, mas sim quem irá fornecer subsídios para que os litigantes identifiquem seus objetivos, defendam seus interesses, criem alternativas para resolver suas diferenças e negociem a melhor opção em que haja a mútua satisfação.

O mediador tem papel coadjuvante em uma sessão de mediação, e seu perfil é o mesmo proposto por Ramos (1982) para um formulador de um sistema social:

[...] não é encarado como uma espécie de benfeitor ou de Pigmalião, que modela um ambiente e diz a seus membros como nele devem viver. É antes, imaginativo como um agente, capaz de facilitar o desenvolvimento de iniciativas livremente geradas pelos indivíduos, passíveis de se amalgamarem, sob a forma de configurações reais.(Ramos, 1982, p.146).

Em outras palavras, Muszkat (2005) também trata do papel social do mediador:

No método integrativo de mediação, o mediador deve ser visto como um agente de transformação social - ou seja, alguém que se apresenta como "instrumento" capaz de proporcionar às partes a oportunidade de adquirir uma nova cultura de solução de conflito.

Revista de Gestão e Secretariado - GeSec, São Paulo, v. 3, n. 1, p 30-53, jan./jun. 2012. 
Como? Promovendo a abertura para a aceitação do conflito e para novas maneiras de abordá-lo, em clima de cooperação (Muszkat, 2005, p. 92).

Fiorelli, Fiorelli e Malhadas Júnior (2008, p. 150) expõem de forma interessante que "o mediador destaca-se pelo senso de equidade; desloca-se com habilidade entre as imposições da ética, da moral, da justiça e do bem-estar dos envolvidos, em um movimento em que mescla arte, filosofia e técnica".

Dentre as características que fazem parte do perfil do mediador, segundo Fiorelli, Fiorelli e Malhadas Júnior (2008), estão:

- Idade - algumas questões ligadas à idade podem influenciar na escolha do mediador. São elas: identificação dos litigantes com o mediador, descontração, sintonia de linguagem (fator determinante em uma sessão de mediação, entretanto não depende apenas da faixa etária), vivência e experiência de relacionamento interpessoal.

- Formação superior - representa uma maior garantia de que o mediador está mais capacitado para: interpretar com precisão a linguagem tanto falada quanto escrita; elaborar metáforas e analogias, a fim de promover a melhor interpretação entre os interesses mediados; raciocinar abstratamente; analisar e promover a síntese das discussões e redigir acordos de forma apropriada. Todavia, esse item não garante a existência da afinidade e da sensibilidade.

- Competência interpessoal - é caracterizada pela maneira objetiva, segura, persistente e eficaz, pela qual o mediador administra a sessão de mediação.

- Domínio da língua portuguesa - é indispensável, uma vez que proporcionará ao mediador: a compreensão da linguagem, rapidez na leitura e compreensão de documentos, competência para redigir acordos, facilidade para expor suas opiniões e criar distinção em relação a seu papel.

- Conhecimentos mínimos de Direito - é conveniente, mas não totalmente obrigatório.

- Conhecimentos e competências a respeito de mediação e suas técnicas - são elas: domínio do conceito de mediação, identificação da aplicabilidade da mediação, compreensão do papel do mediador, ciência de suas responsabilidades, habilidades 
de comunicação interpessoal, domínio de técnicas de condução de reuniões, criatividade para gerar opções, capacidade de tomar decisões e elaborar acordos.

- Sintonia cultural - significa estar em sintonia com a realidade dos mediandos, ou seja, entender todo o contexto que envolve as partes.

- Imagem pública - o mediador deve ter conduta pautada na ética profissional, a fim de dar credibilidade ao seu papel.

- Resistência física - diz respeito à saúde física e psíquica. O mediador deve preservar sua capacidade de concentração, a fim de não prejudicar o andamento da sessão. Assim, é importante que seu estado de saúde seja adequado para enfrentar qualquer tipo de situação.

- Resistência ao estresse emocional - é essencial para o sucesso de uma sessão de mediação que o mediador mantenha o autocontrole, pois o estresse em nada contribuirá.

- Paciência - em algumas sessões serão demasiadas as queixas e comportamentos inadequados. O mediador, por mais ilógicos, preconceituosos, intolerantes e imediatistas que sejam os mediandos, deve manter postura adequada e comportar-se de acordo com seu papel.

- Autoconfiança - o mediador autoconfiante desperta a confiança nos mediandos, fator essencial para o sucesso da mediação.

Fiorelli, Fiorelli e Malhadas Júnior (2008) argumentam que o mediador tem como objetivos: apaziguar, estabelecer a comunicação, estabelecer a cooperação e equilibrar a mesa de negociação. Ainda segundo os autores são funções do mediador: o acolhimento, a organização, a prestação de informações e esclarecimentos, a administração das participações dos mediandos, a ampliação e a compreensão do problema, o estabelecimento de sintonia emocional, o desenvolvimento de soluções de forma cooperada e o favorecimento de acordos satisfatórios. 
Em síntese, o mediador dentro de um ambiente específico, tem papel de relevância, uma vez que é ele quem irá "preparar" as partes para a solução de seus conflitos. Vale retomar que não cabe a ele saber quem está ou não com a razão, mas sim colaborar para a solução do problema. Nesse sentido, compreende-se que o mediador usará seu conhecimento somente para promover, delinear e facilitar as atuações. No cenário da mediação, as partes serão as protagonistas e estão protegidas da intervenção do terceiro. O resultado final será mérito dos mediandos.

\section{O PROFISSIONAL DE SECRETARIADO EXECUTIVO COMO MEDIADOR DE CONFLITOS}

Após análise do histórico e perfil profissional de Secretariado Executivo, da gestão e resolução de conflitos, na qual se destacou o método da mediação, é momento de convergir todo o exposto, ou seja, comparar as características requeridas de um mediador às habilidades e competências inerentes ao perfil do profissional de Secretariado para avaliar se este tem condições de se tornar um hábil mediador de conflitos.

Demonstrou-se, por meio da literatura, que nos últimos anos houve relevante evolução do papel do secretário executivo dentro das organizações. Fato comentado por Natalense (1998, p. 4):

A profissão de secretária é uma das que acompanham o desenvolvimento econômico da humanidade, ao longo dos séculos, sobrevivendo a diferentes realidades. Agora, novamente, revitaliza-se, adaptando-se aos desafios do final do século. Exagero? Não, quando através de pesquisa histórica entendemos esta trajetória, o momento atual e até o futuro da secretária.

Apesar de o secretário executivo ter ainda alguma ligação com o seu passado, no que diz respeito àquelas atividades mais triviais, é importante distinguir entre o que foi importante naquele período e deve ser mantido, e aquilo que deve ser descartado. Nesse sentido, Cortella (2009, p. 73) diz:

Das coisas que vêm do passado é preciso saber separar duas situações: nem tudo que vem do passado é para ser descartado, há aquilo que vem do passado e precisa ser guardado, protegido, levado adiante.

Exemplificando o acima posto, o secretário executivo não deve pensar, por exemplo, que é arcaico redigir uma ata, pois se trata de um documento tradicional. Deve, sim, aprimorar a forma de redigi-la e buscar meios que facilitem a composição do trabalho. Assim, é possível dizer que o profissional de secretariado deve manter o tradicional, porém sem deixar de torná-lo atual.

Revista de Gestão e Secretariado - GeSec, São Paulo, v. 3, n. 1, p 30-53, jan./jun. 2012. 
Nesse sentido, conclui-se que faz parte do novo perfil da profissional de Secretariado Executivo: desenvolver mecanismos que facilitem o desenvolvimento das tarefas diárias, aprimoramento de suas funções e atualização constante. À medida que o secretário executivo for colocando em prática uma personalidade mais "agressiva", mostrando que pode, além de agendar um compromisso, também tomar decisões, ele vai migrar do campo operacional para o estratégico.

Ao alcançar atuação nos níveis mais elevados de uma organização, o profissional de Secretariado Executivo comprovará a amplitude de suas habilidades e atitudes. É na área estratégica que todas as decisões são tomadas e os problemas resolvidos, e é nesse nível que o secretário executivo atuará como mediador de conflitos. Acredita-se que o profissional de secretariado, por toda sua história, na qual os conflitos foram protagonistas; pelo conhecimento que tem em diversas áreas, proporcionado pela característica de multidisciplinaridade do curso de graduação em que se formou; pela vasta abrangência de suas habilidades e pelas atitudes corretas, embasadas na ética e no profissionalismo, está apto para a atuação na mediação de conflitos.

Comparando-se as características que identificam o mediador citadas na seção anterior com as do secretário executivo (Quadro 1), fica evidente que esse profissional tem condições de desenvolver um trabalho eficiente nesse campo. Todos os itens caracterizadores do mediador, apontados por Fiorelli, Fiorelli e Malhadas Júnior (2008), fazem parte do novo perfil do profissional de secretariado, e sua aplicabilidade pode ser observada na realização da tarefa cotidiana, conforme demonstra o quadro a seguir.

\begin{tabular}{|c|c|c|}
\hline \multicolumn{3}{|c|}{$\begin{array}{l}\text { QUADRO COMPARATIVO DAS CARACTERÍSTICAS DO } \\
\text { PERFIL DO MEDIADOR/SECRETÁRIO EXECUTIVO }\end{array}$} \\
\hline CARACTERÍSTICAS & MEDIADOR & SECRETÁRIO EXECUTIVO \\
\hline Idade & $\begin{array}{l}\text { Algumas questões ligadas à idade podem } \\
\text { influenciar na escolha do mediador, são } \\
\text { elas: identificação dos litigantes com o } \\
\text { mediador, descontração, sintonia de } \\
\text { linguagem (fator determinante em uma } \\
\text { sessão de mediação, entretanto não } \\
\text { depende apenas da faixa etária), vivência } \\
\text { e experiência de relacionamento } \\
\text { interpessoal. }\end{array}$ & $\begin{array}{l}\text { A idade ideal, para administrar uma } \\
\text { sessão de mediação, varia de acordo } \\
\text { com cada tipo de situação. O } \\
\text { profissional de secretariado neste } \\
\text { ponto tem as mesmas condições que } \\
\text { qualquer outro profissional. }\end{array}$ \\
\hline
\end{tabular}




\begin{tabular}{|c|c|c|}
\hline $\begin{array}{l}\text { Formação } \\
\text { superior }\end{array}$ & $\begin{array}{l}\text { Garantia de que o mediador está mais } \\
\text { capacitado para: interpretar com precisão } \\
\text { a linguagem falada tanto falada, quanto } \\
\text { escrita; elaborar metáforas e analogias, a } \\
\text { fim de promover a melhor interpretação } \\
\text { entre os interesses mediados, raciocinar } \\
\text { abstratamente, analisar e promover a } \\
\text { síntese das discussões e redigir acordos de } \\
\text { forma apropriada. }\end{array}$ & $\begin{array}{l}\text { O profissional de Secretariado } \\
\text { Executivo só alcança tal status se tiver } \\
\text { formação superior. }\end{array}$ \\
\hline $\begin{array}{l}\text { Competência } \\
\text { interpessoal }\end{array}$ & $\begin{array}{l}\text { É caracterizada pela maneira objetiva, } \\
\text { segura, persistente e eficaz, pela qual o } \\
\text { mediador administra a sessão de } \\
\text { mediação. }\end{array}$ & $\begin{array}{l}\text { É sem dúvida uma das características } \\
\text { do profissional de secretariado. De } \\
\text { acordo com a posição que ocupa } \\
\text { dentro de uma organização o } \\
\text { secretário(a) executivo(a) trabalha de } \\
\text { forma objetiva, segura, persistente e } \\
\text { eficaz. }\end{array}$ \\
\hline $\begin{array}{l}\text { Domínio da língua } \\
\text { portuguesa }\end{array}$ & $\begin{array}{l}\text { É indispensável, uma vez que } \\
\text { proporcionará ao mediador: a } \\
\text { compreensão da linguagem, rapidez na } \\
\text { leitura e compreensão de documentos, } \\
\text { competência para redigir acordos, } \\
\text { facilidade para expor suas opiniões e criar } \\
\text { distinção em relação do seu papel. }\end{array}$ & $\begin{array}{l}\text { O conhecimento da linguagem padrão } \\
\text { é indispensável para exercer a função. } \\
\text { O profissional de Secretariado } \\
\text { Executivo redige documentos, revisa- } \\
\text { os e atende aos clientes tanto internos } \\
\text { quanto externos. É imprescindível que } \\
\text { ele(a) saiba se comunicar de forma } \\
\text { adequada. }\end{array}$ \\
\hline $\begin{array}{l}\text { Conhecimentos } \\
\text { mínimos de } \\
\text { Direito. }\end{array}$ & $\begin{array}{l}\text { É conveniente, mas não totalmente } \\
\text { obrigatório. }\end{array}$ & $\begin{array}{l}\text { Os cursos de graduação em } \\
\text { Secretariado Executivo, de diversas } \\
\text { instituições de ensino superior contam } \\
\text { com, pelo menos, uma disciplina de } \\
\text { direito em seus currículos. }\end{array}$ \\
\hline $\begin{array}{c}\text { Conhecimentos e } \\
\text { competências a respeito } \\
\text { de mediação e suas } \\
\text { técnicas }\end{array}$ & $\begin{array}{l}\text { Domínio do conceito de mediação, } \\
\text { identificação da aplicabilidade da } \\
\text { mediação, compreender o papel do } \\
\text { mediador, estar ciente de suas } \\
\text { responsabilidades, habilidades de } \\
\text { comunicação interpessoal, domínio de } \\
\text { técnicas de condução de reuniões, } \\
\text { criatividade para gerar opções, ser capaz } \\
\text { de tomar decisões e elaborar acordos. }\end{array}$ & $\begin{array}{l}\text { Todo e qualquer profissional que } \\
\text { intenciona trabalhar com a mediação } \\
\text { de conflitos, terá de se especializar nos } \\
\text { estudos sobre o tema. Certamente, o } \\
\text { profissional de secretariado é ciente de } \\
\text { suas responsabilidades, tem } \\
\text { habilidades de comunicação } \\
\text { interpessoal, tem domínio de técnicas } \\
\text { de condução de reuniões, é criativo, é } \\
\text { capaz de tomar decisões e elaborar } \\
\text { acordos. }\end{array}$ \\
\hline Sintonia cultural & $\begin{array}{l}\text { Estar em sintonia com a realidade dos } \\
\text { mediandos, ou seja, entender todo o } \\
\text { contexto que os envolve. }\end{array}$ & $\begin{array}{l}\text { O profissional de Secretariado } \\
\text { Executivo está sempre em sintonia } \\
\text { com o ambiente em que está inserido e } \\
\text { também, com todos aqueles ligados as } \\
\text { atividades da organização. }\end{array}$ \\
\hline
\end{tabular}




\begin{tabular}{|c|c|c|}
\hline Imagem pública & $\begin{array}{l}\text { O mediador deve ter conduta pautada na } \\
\text { ética profissional, a fim de dar } \\
\text { credibilidade ao seu papel. }\end{array}$ & $\begin{array}{l}\text { O profissional de Secretariado } \\
\text { Executivo tem plena noção de conduta, } \\
\text { principalmente no que diz respeito à } \\
\text { ética profissional. }\end{array}$ \\
\hline Resistência física & $\begin{array}{l}\text { Diz respeito à saúde física e psíquica. O } \\
\text { mediador deve preservar sua capacidade } \\
\text { de concentração, a fim de não prejudicar o } \\
\text { andamento da sessão. }\end{array}$ & $\begin{array}{l}\text { O profissional de secretariado está } \\
\text { sempre atento ao que diz respeito à sua } \\
\text { saúde física e psíquica. A capacidade } \\
\text { de concentração é importantíssima, } \\
\text { uma vez que é ele(a) o(a) responsável } \\
\text { pela interface entre os dirigentes, } \\
\text { equipe de trabalho e clientes. }\end{array}$ \\
\hline $\begin{array}{l}\text { Resistência ao estresse } \\
\text { emocional }\end{array}$ & $\begin{array}{l}\text { É essencial para o sucesso de uma sessão } \\
\text { de mediação, que o mediador mantenha o } \\
\text { autocontrole, estressar-se não contribuirá } \\
\text { em nada. }\end{array}$ & $\begin{array}{l}\text { O secretário executivo convive com } \\
\text { situações de estresse emocional } \\
\text { diariamente. É ele o organizador e } \\
\text { harmonizador do ambiente de trabalho. } \\
\text { Sendo assim, sabe como manter o } \\
\text { autocontrole. }\end{array}$ \\
\hline Paciência & $\begin{array}{l}\text { Em algumas sessões serão demasiadas as } \\
\text { queixas e comportamentos inadequados. } \\
\mathrm{O} \text { mediador, por mais ilógicos, } \\
\text { preconceituosos, intolerantes e } \\
\text { imediatistas que sejam os mediandos, } \\
\text { deve manter postura adequada e } \\
\text { comportar-se de acordo com seu papel. }\end{array}$ & $\begin{array}{l}\text { Uma das características primordiais do } \\
\text { profissional de secretariado. Ele é o } \\
\text { responsável por maximizar e otimizar } \\
\text { tanto o tempo do seu superior, quanto } \\
\text { o seu próprio. Dessa forma não adianta } \\
\text { "atropelar" o trabalho, pois a } \\
\text { possibilidade de erros será muito } \\
\text { maior. O secretário executivo é } \\
\text { também, aquele que irá ouvir as mais } \\
\text { variadas "queixas" tanto de superiores } \\
\text { quanto dos demais colaboradores. }\end{array}$ \\
\hline Autoconfiança & $\begin{array}{l}\text { O mediador autoconfiante desperta a } \\
\text { confiança nos mediandos, fator essencial } \\
\text { para o sucesso da mediação. O Mediador } \\
\text { autoconfiante: } \\
\text { - incentiva a participação e se mantém } \\
\text { aberto ao diálogo; } \\
\text { - não se refugia nos temos técnicos; } \\
\text { - mantém o olhar firme, a fala pausada e } \\
\text { direta; } \\
\text { - estimula o questionamento; } \\
\text { - demonstra equilíbrio e ponderação; } \\
\text { - combina ousadia com prudência; } \\
\text { - exerce plenamente sua sensibilidade; } \\
\text { - dispensa o recurso a regulamentos que } \\
\text { apenas servem para ocultar a insegurança; } \\
\text { - reconhece os próprios erros; } \\
\text { - aperfeiçoa-se continuamente, porque } \\
\text { não teme rever conceitos. }\end{array}$ & $\begin{array}{l}\text { O secretário executivo é considerado o } \\
\text { fornecedor de subsídios para a tomada } \\
\text { de decisões; para tanto é necessária } \\
\text { muita autoconfiança em relação a suas } \\
\text { atitudes. Nesse sentido, Fiorelli, } \\
\text { Fiorelli e Malhadas Júnior (2008, p. } \\
\text { 155) cita algumas características do } \\
\text { mediador autoconfiante, as quais são } \\
\text { idênticas à postura a ser adotada pelo } \\
\text { do profissional de secretariado. }\end{array}$ \\
\hline
\end{tabular}

Quadro 2 - Quadro comparativo das características do perfil do mediador/secretário executivo. Fonte: Elaboração da autora com adaptações baseadas em Fiorelli, Fiorelli e Malhadas Júnior (2008). 
Semelhante ao que conclui Fiorelli, Fiorelli e Malhadas Júnior (2008) em relação ao mediador, o profissional de Secretariado Executivo também tem as funções de apaziguar, estabelecer a comunicação, estabelecer a cooperação e equilibrar o ambiente, visto que é ele talvez um dos poucos colaboradores na organização que mantém contato com todos os outros (clientes internos e externos).

Segundo Natalense (1998), o secretário é empreendedor. A afirmação é relevante neste momento, pois as características que o definem como tal comprovarão e sintetizarão o objetivo deste estudo. Assim sendo, ser empreendedor, para a autora, significa ser:

\footnotetext{
- Oportunista - percebe as oportunidades e as aproveita.

- Polivalente - executa diversas etapas de uma mesma tarefa. É capaz de assessorar as mais diferentes áreas com a mesma competência.

- Entusiasta - vibra com aquilo que realiza, tem orgulho do seu trabalho, ama a profissão, comemora as pequenas vitórias.

- Informada - domina as informações com relação à empresa, ao mercado em que atua, a sua categoria profissional; é integrada aos acontecimentos da sociedade em geral.

- Experimenta - Varia, arrisca novas formas de fazer as coisas, reinventa o que faz. Dá ênfase ao positivo. Trabalha com bom humor, usa de gentilezas no dia a dia.

- Eficaz - trabalha com eficiência e eficácia, ou seja, preocupada com tempo, custo e qualidade. Sobrevive criando, surpreendendo continuadamente. Tem tempo para pesquisar o futuro. É capaz de orquestrar grupos. Tem clareza de metas e padrões de desempenho. Tem capacidade para: educar, desenvolver pessoas e gerar aprendizagem coletiva; energizar pessoas e os ambientes; comunicar, sensibilizar e disseminar idéias.

- É perseverante. (Natalense, 1998, pp. 49-50).
}

$\mathrm{Na}$ comparação promovida pelo quadro abaixo observa-se que existem dois tipos de profissionais de Secretariado Executivo, os que estão "aptos" a assumir a posição de mediadores, ou seja, os empreendedores, e os conservadores, os quais dificilmente poderão assumir qualquer tipo de desafio.

\section{CARACTERÍSTICAS DO PROFISSIONAL DE SECRETARIADO}

\begin{tabular}{|c|c|}
\hline CONSERVADORES & EMPREENDEDORES \\
\hline $\begin{array}{l}\text { - Trabalha para pessoas } \\
\text { - Interage com chefes } \\
\text { - Trabalha isolada } \\
\text { - Evita riscos } \\
\text { - Direciona a sua atuação para garantir o seu emprego } \\
\text { - Motivada por símbolos de poder } \\
\text { - Centralizadora } \\
\text { - Desculpa-se pelos erros } \\
\text { - Faz as coisas bem feitas } \\
\text { - Economiza os recursos }\end{array}$ & $\begin{array}{l}\text { - Trabalha para a empresa } \\
\text { - Interage com clientes, fornecedores e parceiros } \\
\text { - Trabalha em equipes } \\
\text { - Assume riscos moderados, investe } \\
\text { - Não tem medo de ser demitida } \\
\text { - Motivada por metas } \\
\text { - Cria alternativas para o trabalho em equipe, } \\
\text { desenvolvendo pessoas } \\
\text { - Faz dos seus erros uma forma de aprendizado e } \\
\text { segue em frente }\end{array}$ \\
\hline
\end{tabular}

Revista de Gestão e Secretariado - GeSec, São Paulo, v. 3, n. 1, p 30-53, jan./jun. 2012. 
- Cumpre o seu dever

- Trabalha em função da sua personalidade
- Faz as coisas certas nos momentos certos

- Maximiza a utilização dos recursos

- Obtém resultados

- Trabalha para alcançar objetivos, produzindo resultados e autorrealização

Quadro 3 - A secretaria conservadora x empreendedora.

Fonte: Adaptado de Natalense (1998, p. 50-51).

Neiva e D’Elia (2009) relatam que o secretário executivo ocupa uma posição bastante privilegiada no ambiente organizacional, isto é, trabalha diretamente no nível estratégico de uma organização, e, assim sendo, está sempre envolvido com os mais diversos tipos de negociação.

O campo fértil para a implementação das ideias empreendedoras está cada vez mais visível nas empresas e organizações. Por atuar ao lado do poder, gerenciando informações, o profissional secretário tem acesso a uma gama rica e diversa de ideias, fatos, situações, aliados à convivência com as diferenças individuais (Neiva e D'elia, 2009, p. 170).

Por fim, compreende-se que a definição de empreendedorismo é descrita por vários autores, entretanto, em sua essência, significa identificar a possibilidade de criar algo novo. Já o intraempreendedorismo tem como ideal fazer algo novo dentro de uma empresa já constituída. Tais definições são, justamente, a essência desta pesquisa, ou seja, comprovar que o profissional de secretariado pode "criar" novas oportunidades para diversificar sua carreira.

\section{CONSIDERAÇÕES FINAIS}

Ao final desta pesquisa é possível perceber a complexidade que envolve o tema proposto. Embora o profissional de secretariado enfrente situações de conflito em qualquer uma de suas esferas, cotidianamente; lidar com pessoas que têm percepções e necessidades diversas e, ainda, auxiliar na busca por uma resolução satisfatória para ambas as partes, é algo que exige, entre outros elementos, autocontrole, autoconhecimento, equilíbrio e senso ético.

Nesse sentido, este estudo propôs verificar se as características do atual perfil do profissional de Secretariado Executivo são compatíveis com as requeridas para um mediador de conflitos, possibilitando, assim, àquele profissional - o secretário - outra oportunidade de atuação dentro da carreira. 
Salienta-se que não está implícito nesta proposta um desvio de função em relação às atividades do profissional de secretariado, mas sim um acréscimo que possa valorizar aquele que vem, ao longo da história, buscando o aprimoramento constante de suas funções, incorporando a elas fundamentos que possibilitem a evolução profissional.

De acordo com o estudo, evidenciou-se o amadurecimento do profissional de secretariado e a demonstração de que não há temor frente à mudança e à revisão de conceitos. A transversalidade de conhecimento, a resolutividade, a polivalência, a inovatividade e a multifuncionalidade são exemplos de novas competências agregadas ao contemporâneo perfil do profissional de Secretariado Executivo, as quais, a partir de suas definições, habilitam, previamente, o secretário executivo a exercer a mediação de conflitos.

A fim de atingir o objetivo proposto para esta pesquisa: "identificar se o profissional de Secretariado Executivo tem competências e habilidades para exercer o papel de mediador de conflitos", examinou-se a profissão de Secretariado Executivo, sua história, principais características e diferença de perfis do profissional de secretariado no decorrer dos anos.

Trabalhou-se ainda a gestão de conflitos, tratando dos elementos que caracterizam situações conflitantes e, também, sua administração, com ênfase para a mediação e para papel do mediador, por se tratar de ponto específico deste estudo.

Entretanto, é importante salientar que apesar das vantagens apresentadas para tal método de resolução de conflitos, a mediação não é ato perfeito, ou seja, não é infalível e nem a solução para todos os problemas; por isso, não se aplica a todas as situações conflitivas.

Por fim, averiguou-se, por meio da comparação, se os perfis do profissional de secretariado e do mediador eram similares a ponto de aquele estar apto a assumir a função de mediador de conflitos.

Constatou-se que o profissional de Secretariado Executivo intermedeia as relações do gestor com ambientes interno e externo, possui conhecimentos multidisciplinares, é um organizador, empreendedor, assume responsabilidades, tem iniciativa, é criativo, possui autonomia para tomar decisões e solucionar problemas. Em outras palavras, o secretário executivo, por meio da aprendizagem constante e de ações proativas, qualificou-se, e tal fato permite-lhe almejar níveis mais estratégicos dentro das organizações.

Segundo exposto no contexto deste estudo e de acordo com Fiorelli, Fiorelli e Malhadas Júnior (2008), o mediador tem as funções de apaziguar, estabelecer a comunicação, equilibrar e estabelecer a cooperação. A comparação entre os perfis dos atores da pesquisa demonstrou que o 
papel exercido pelo profissional de Secretariado Executivo no ambiente organizacional é bastante semelhante àquele do mediador de conflitos.

Dessa forma, ao final da análise, averiguou-se que as características que fazem parte do novo perfil do profissional de secretariado e aquelas de um mediador de conflitos são compatíveis. E, sendo assim, conclui-se que o profissional de Secretariado Executivo tem condições de ser um mediador. Observa-se, entretanto, que, apesar da experiência empírica com conflitos e o uso do bom senso no que se refere à resolução de situações desse tipo, é necessário a ele, para atuar na mediação, capacitação específica sobre o tema, tal qual qualquer outro profissional que se habilite a tal propósito.

Refletindo sobre todo o exposto, é bastante estimulante pensar que o profissional de Secretariado Executivo está conquistando novos espaços e principalmente sendo cada vez mais valorizado pelo mercado de trabalho.

Várias são as possibilidades para o profissional de Secretariado Executivo no ambiente profissional, visto o caráter multifuncional de sua carreira. Basta a ele que se identifique e se afine com a função para que se garanta o sucesso. Uma dentre as alternativas é a sugerida por esta pesquisa - a atuação na mediação de conflitos, entretanto, tantas outras, como por exemplo, na área do assessoramento, gestão, empreendedorismo e consultoria são possíveis. O importante é que o profissional possa democratizar suas visões de futuro, o qual é incerto e complexo, porém pode e deve ser organizado.

\section{REFERÊNCIAS}

Brasil. Lei n. 7.337, de 30 de setembro 1985. Dispõe sobre o Exercício da profissão de secretário, e dá outras providências. Disponível em:

<http://www.planalto.gov.br/ccivil_03/Leis/L7377.htm>. Acesso em: 24 fev. 2010.

Carvalho, Antonio Pires \& Grisson, Diller. (2002). Manual de secretariado executivo. São Paulo: Difusão Cultural do Livro Ltda.

Chiavenato, Idalberto. (2000). Gestão de pessoas: o novo papel dos recursos humanos nas organizações. Rio de Janeiro: Campus.

Revista de Gestão e Secretariado - GeSec, São Paulo, v. 3, n. 1, p 30-53, jan./jun. 2012. 
Ching, Rose. (2006). A arte de secretariar: tudo o que você precisa saber para ser uma secretária de sucesso! São Paulo: Novatec.

Cortella, Mário Sérgio. (2009). Qual a tua obra?: inquietações propositivas sobre gestão, liderança e ética. 7a ed. Petrópolis, Rj: Vozes.

Davies, Christine. A secretária do futuro. Disponível em: <http://br.hsmglobal.com/notas/45857-asecretaria-do-futuro>. Acesso em: 13 ago. 2010.

Fiorelli, José Osmir; Fiorelli, Maria Rosa \& Malhadas Júnior, Marcos Julio Olivé. (2008). Mediação e solução de conflitos: teoria e prática. São Paulo: Atlas.

Gil, Antonio Carlos. (1991) Como elaborar projetos de pesquisa. 3a ed. São Paulo: Atlas. . (2010). Como elaborar projetos de pesquisa. São Paulo: Atlas.

Guimarães, Márcio Eustáquio.(1999) O livro azul da secretária moderna. 16a ed. São Paulo: Érica.

Moscovici, Fela.(1997). Desenvolvimento interpessoal: treinamento em grupo. 7a ed. rev. e ampl. Rio de Janeiro: Jose Olympio.

Muskat, Malvina Ester. (2005) Guia prático de mediação de conflitos: em famílias e organizações. São Paulo: Summus.

Natalense, Liana.(1998) A secretária do futuro. Rio de Janeiro: Qualitymark.

Neiva, Edméa Garcia \& D'elia, Maria Elizabete Silva. (2009). As novas competências do profissional de secretariado. 2a ed. São Paulo: IOB.

Ramos, Alberto Guerreiro. A nova ciência das organizações. Rio de Janeiro: FGV, 1982.

Robbins, Stephen P. (2000). Administração: mudanças e perspectivas. São Paulo: Saraiva. . (2005). Comportamento organizacional. 11a ed Rio de Janeiro: Pearson Prentice Hall.

Senge, Peter. (2006). A quinta disciplina. 22a ed. Rio de Janeiro: Best Seller.

Serva, Maurício Roque de Oliveira. (1997). A racionalidade substantiva demonstrada na prática administrativa. In: Revista de administração de empresas. São Paulo: EAESP/FGV, v.37, n. 2. 
Wanser, Eliane. (2009). Competências, conhecimentos, habilidades, atitudes de um profissional de Secretariado. Disciplina: Condições de Assessoramento. Especialização em Secretariado Gestão de Pessoas e Processo. Slide 23. Blumenau. Notas de aula ministrada com apresentação de slides.

Wisinski, Jerry. (1995)Como resolver conflitos no trabalho. Rio de Janeiro: Campus. 